PAULO WOO JIN LEE

\title{
SUBORDINAÇÃO E SEUS DESAFIOS \\ NA DINÂMICA DO TRABALHO CONTEMPORÂNEO
}

\author{
DISSERTAÇÃO DE MESTRADO \\ ORIENTADOR: PROFESSOR TITULAR DR. NELSON MANNRICH
}

UNIVERSIDADE DE SÃO PAULO

FACULDADE DE DIREITO

SÃo PaUlo - SP

2019 



\title{
PAULO WOO JIN LEE
}

\section{SUBORDINAÇÃO E SEUS DESAFIOS NA DINÂMICA DO TRABALHO CONTEMPORÂNEO}

\begin{abstract}
Dissertação apresentada à Banca Examinadora do Programa de Pós-Graduação em Direito, da Faculdade de Direito da Universidade de São Paulo, como exigência parcial para obtenção do título de Mestre em Direito, na área de concentração Direito do Trabalho e Seguridade Social, sob a orientação do Professor Titular Dr. Nelson Mannrich.
\end{abstract}

UNIVERSIDADE DE SÃO PAULO

FACULDADE DE DIREITO

SÃo PaUlo - SP 


\section{Catalogação na Publicação \\ Serviço de Processos Técnicos da Biblioteca da}

Faculdade de Direito da Universidade de São Paulo

Lee, Paulo Woo Jin

Subordinação e seus desafios na dinâmica do trabalho contemporâneo / Paulo Whoo Jin Lee. -- São Paulo, 2019.

156 p. ; $30 \mathrm{~cm}$

Dissertação (Mestrado) - Programa de Pós-Graduação em Direito, Faculdade de Direito, Universidade de São Paulo, São Paulo, 2019.

Orientador: Nelson Mannrich.

1. Subordinação jurídica. 2. Subordinação Objetiva. 3. Subordinação estrutural. 4. Livre iniciativa. 5. Valor social do trabalho. I. Mannrich, Nelson, orient. II. Título. 
Nome: PAULO WOO JIN LEE

Título: SUBORDINAÇÃO E SEUS DESAFIOS NA DINÂMICA DO TRABALHO CONTEMPORÂNEO

Dissertação apresentada à Faculdade de Direito da Universidade de São Paulo para obtenção do título de Mestre em Direito

Aprovado em:

Banca Examinadora

Professor (a):

Instituição:

Julgamento:

Professor (a):

Instituição:

Julgamento:

Professor (a):

Instituição:

Julgamento:

Professor (a):

Instituição:

Julgamento: 



\section{AGRADECIMENTOS}

A Deus, por tudo que nos proporciona e pela sua importância nas nossas vidas.

Não existem palavras que consigam expressar minha alegria e honra de ter sido escolhido como um dos orientandos do Professor Nelson Mannrich. Sua paixão e dedicação pelo que faz impressionam, contagiam e causam grande admiração. Serei eternamente grato por todos os incentivos, conhecimentos transmitidos e bons momentos que passamos durante o curso.

Aos meus pais, exemplos de vida, e aos meus irmãos, que sempre estão ao meu lado.

À minha esposa e aos meus filhos, Noah e Sarah, pelo amor e apoio para vencer os desafios do dia a dia.

Aos amigos do mestrado, à Priscila e Vivian em especial, que, de alguma forma, contribuiriam para conclusão do meu mestrado. 

"[...] o centro da gravidade do desenvolvimento do direito não está nem na legislação nem na ciência jurídica, nem na jurisprudência dos tribunais, mas na própria sociedade [...]" (Eugen Ehrlich) 



\section{RESUMO}

Paulo Woo Jin Lee. Subordinação e seus desafios na dinâmica do trabalho contemporâneo. 2019. 156 p. Mestrado - Faculdade de Direito, Universidade de São Paulo, São Paulo, 2019.

O conceito de subordinação jurídica foi forjado juntamente com a história do Direito do Trabalho, de acordo com fatores socioeconômicos que levaram ao surgimento desse ramo especializado das ciências jurídicas. Entretanto, alterações no modo de produzir fizeram com que parte da doutrina e jurisprudência defendesse sua reformulação, para aumentar o número de trabalhadores cobertos pela legislação trabalhista, tendo em vista a existência de grande contingente de hipossuficientes que, atualmente, se encontram excluídos por não preencherem os requisitos da relação de emprego ou em condições precárias por causa da terceirização, como ainda sustenta essa corrente. A proposta é louvável, mas incompatível com a realidade produtiva, econômica e social do mundo contemporâneo, dado que as modernas formas de organização da produção e avanços tecnológicos não permitem mais a concentração improdutiva e cara de todas as etapas de elaboração de bens e serviços em uma única e gigantesca empresa. Assim, como o conceito clássico de subordinação ainda se mostra adequado à conjuntura atual, em vez de alterá-lo, é imperiosa a adoção de figura intermediária entre autônomo e subordinado, como fizerem outros países, de modo a ampliar a proteção aos que dela necessitam.

Palavras-chave: Subordinação Jurídica. Subordinação Objetiva. Subordinação Estrutural. Livre Iniciativa. Valor Social do Trabalho. 


\begin{abstract}
Paulo Woo Jin Lee. Subordination and its challenges in the dynamics of contemporary work. 2019. 156 p. Master - Faculty of law, University of São Paulo, São Paulo, 2019.
\end{abstract}

The concept of juridical subordination was engendered together with the history of Employment Law, in accordance with the social-economic factors that led to the emergence of this specialized area of Legal Sciences. However, changes in the modes of production have made part of the doctrine and jurisprudence defend its review, in order to increase the number of workers covered by employment legislation, since there is a great number of disadvantaged parties who are nowadays excluded from the system for not meeting the necessary employment requirements or who are in precarious situations due to outsourcing, as this school of thought sustains. The proposal is laudable, but incompatible with the productive, economic and social reality of the contemporary world, as the modern forms of organizing productions and technological advancements no longer allow the improductive and costly concentration of all the phases of goods and service elaboration in one giant enterprise. Thus, since the classic concept of subordination is still adequate to the current scenario, instead of altering it, it is vital to adopt an intermediate role between outsourced worker and subordinate, as done in other countries, so as to increase the protection of those who need it.

Key words: Juridical subordinaton. Objetive subordination. Structural subordination. Free initiative. Social value of work. 


\section{SUMÁRIO}

INTRODUÇÃO

11

\section{CAPÍTULO 1 | BREVE HISTÓRICO DA EVOLUÇÃO DO DIREITO DO TRABALHO

1. EVOLUÇÃO HISTÓRICA DO TRABALHO HUMANO ......................................... 15

2. ORIGEM DO DIREITO DO TRABALHO: REVOLUÇÃO INDUSTRIAL ............. 19

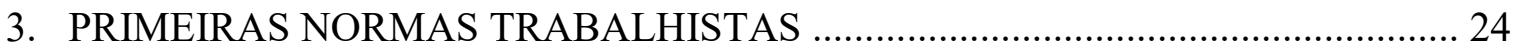

4. REDEFINIÇÃO DO PAPEL DO DIREITO DO TRABALHO .................................... 25

CAPÍTULO 2 | ELEMENTOS DA RELAÇÃO DE EMREGO ……......... 31

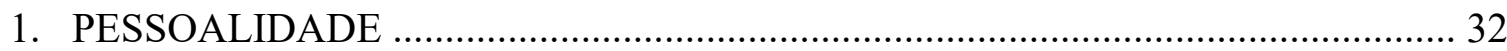

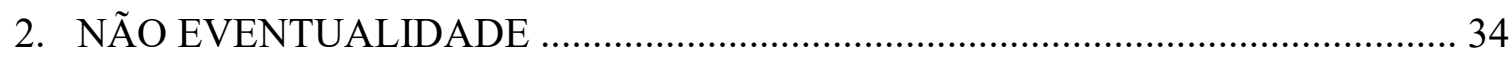

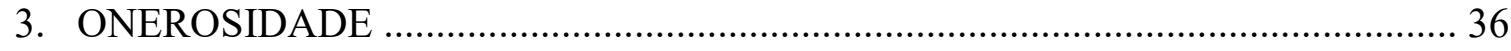

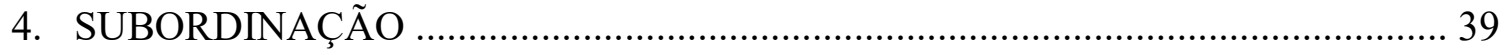

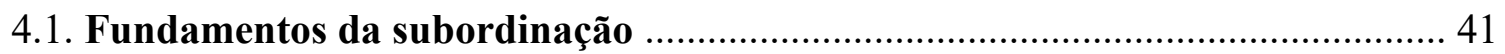

5. CLASSIFICAÇÃO DA SUBORDINAÇÃO ………………………………….... 43

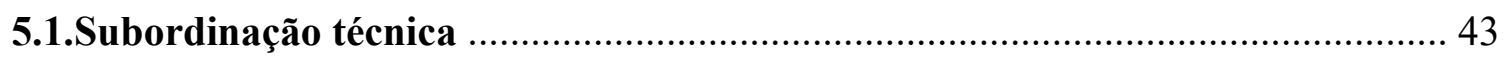

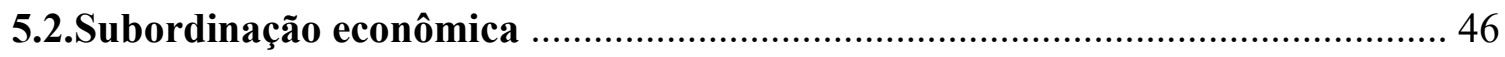

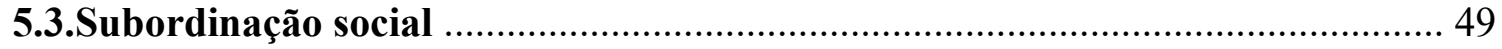

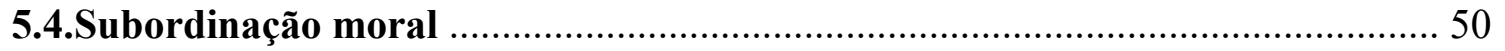

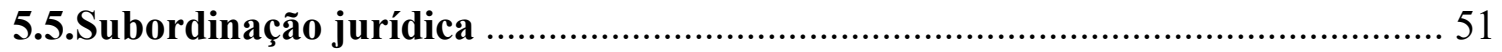

5.5.1. Origem da subordinação jurídica ………………………………………...... 54

5.5.2. Subordinação jurídica como resultado do contrato de trabalho ……………….... 55

5.5.3. Intensidade da subordinação jurídica ……………………………………....... 57

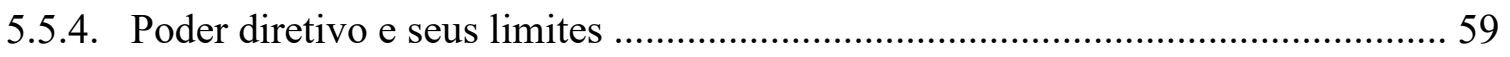

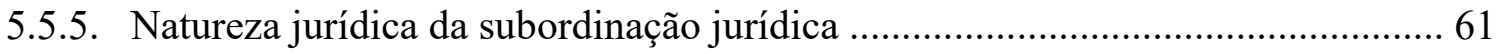

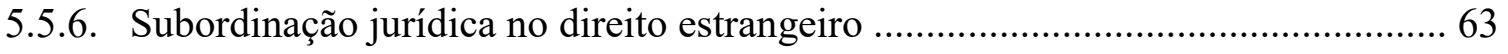

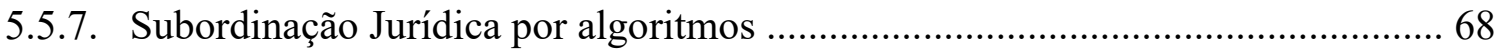




\section{CAPÍTULO 3 | RELAÇÕES CONTEMPORÂNEAS DE TRABALHO E TEORIAS EXPANSIONISTAS DO CONCEITO DE SUBORDINAÇÃO}

1. ALTERAÇÃO NO MUNDO DO TRABALHO 73

1.1.Reflexos das alterações no mundo do trabalho na legislação e

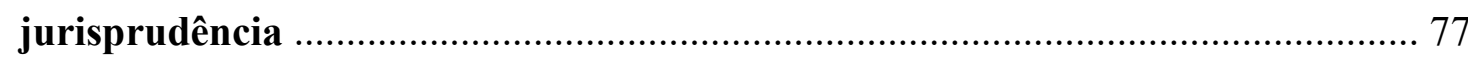

2. CAMINHOS PARA ENFRENTAR AS ALTERAÇÕES NO MUNDO DO TRABALHO 80

3. TEORIAS EXPANSIONISTAS DO CONCEITO DE SUBORDINAÇÃO ................. 84

3.1. Subordinação objetiva .85

3.2. Subordinação estrutural 87

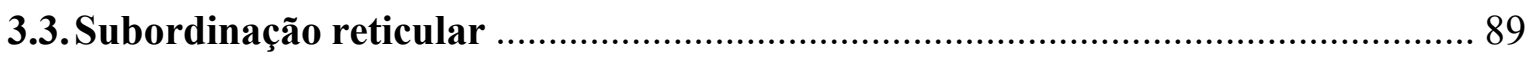

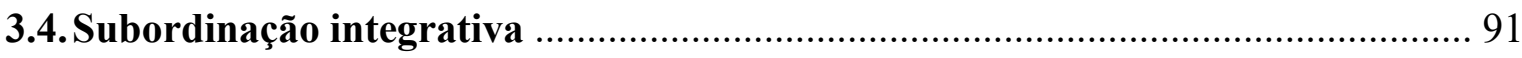

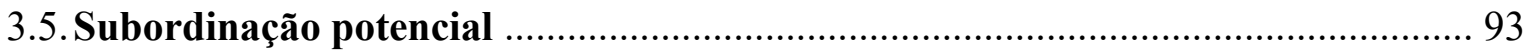

4. CRÍTICAS ÀS TEORIAS EXPANSIONISTAS DO CONCEITO DE

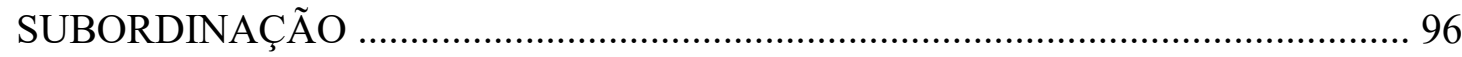

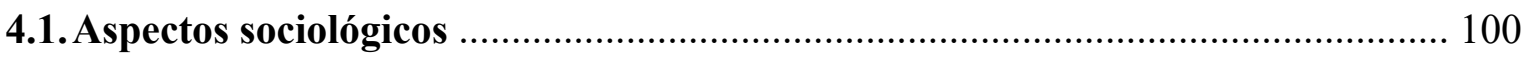

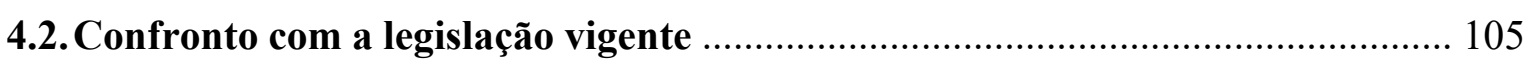

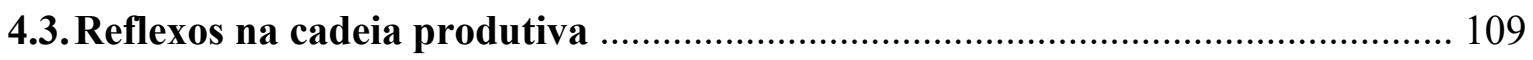

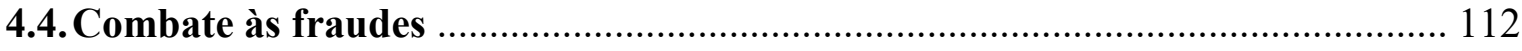

CAPÍTULO 4 | NECESSIDADE DE INCORPORAÇÃO DE NOVAS MODALIDADES DE NORMATIZAÇÃO DO TRABALHO CONTEMPORÂNEO 115

1. CRISE DA DIVISÃO BINÁRIA: SUBORDINAÇÃO VERSUS AUTONOMIA 115

2. EXPERIÊNCIA ESTRANGEIRA 121

2.1. Parassubordinação 121

2.2. Trabalho autônomo economicamente dependente (TRADE) 126 


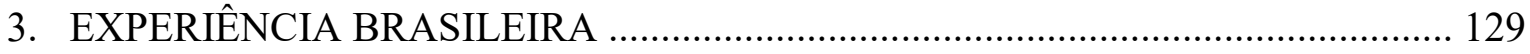

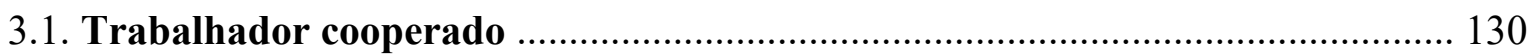

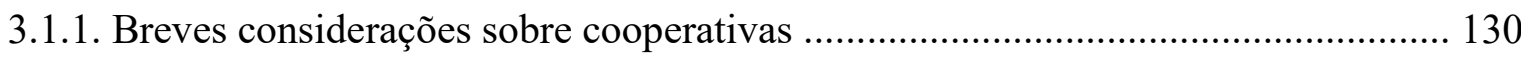

3.1.2. Lei $n^{\circ}$ 12.690/12 | Ampliação da tutela social ao cooperado .................................. 134

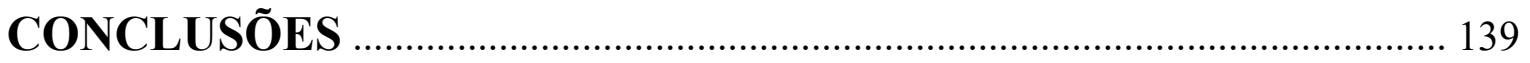

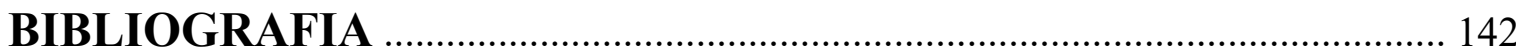





\section{INTRODUÇÃO}

Escolheu-se para a temática desta dissertação de Mestrado o estudo da subordinação no âmbito do contrato de emprego, dado tratar-se do principal requisito identificador da espécie de trabalho tutelada pelo sistema de proteção social, ou seja, por ser a "pedra angular do grande edifício do Direito do Trabalho" 1.

A importância do tema está no fato de a subordinação restringir o campo de atuação do Direito do Trabalho ao trabalhador subordinado, deixando os autônomos, mesmo os economicamente dependentes, excluídos da sua proteção.

Entretanto, diante das mudanças socioeconômicas e das evoluções tecnológicas que causaram profundas transformações no sistema capitalista de produção e, consequentemente, na forma de trabalhar, discutem-se mecanismos para atender as novas necessidades na regulação do trabalho humano, o que produzirá grandes impactos não só no Direito do Trabalho, mas também na economia e na organização interna das empresas.

Parte da doutrina e jurisprudência, sem qualquer fundamento legal, com o argumento de que o tradicional instituto é insuficiente para atender a sociedade pósindustrial, modificou o conceito de subordinação jurídica consagrado e amadurecido ao longo da história, para alargar o espectro de incidência do Direito do Trabalho aos autônomos e combater a precarização do trabalho que entendem ocorrer por meio do instituto da terceirização.

Ocorre que o autônomo e o subordinado são econômica e socialmente muito diferentes, o que justifica a ausência de tratamento unitário, do ponto de vista legal. A própria evolução histórica e social que deu origem ao Direito do Trabalho, com fins de proteção do trabalhador dependente, demonstra peculiaridades desse ramo do direito que não podem ser aplicadas ao autônomo.

\footnotetext{
${ }^{1}$ MANNRICH, Nelson. Reinventando o Direito do Trabalho: novas dimensões do trabalho autônomo. In: FREDIANI, Yone (coord.). A valorização do trabalho autônomo e a livre-iniciativa. Porte Alegre: Magister, 2015. p. 244.
} 
Desse modo, o presente estudo se justifica porque exporá críticas às teorias expansionistas do conceito de subordinação, tendo em vista que contrários à legislação vigente e o fato de que tais teorias causam impactos prejudiciais aos hipossuficientes que pretendem proteger.

O estudo analisará o longo e cuidadoso processo de maturação da subordinação jurídica, advinda da doutrina e que recebeu amplo suporte jurisprudencial, com base nos eventos que levaram inclusive à criação do Direito do Trabalho, pelo que não pode ser desconsiderado.

A dissertação abordará a necessidade de atualização da lei brasileira para a regulamentação das novas formas de trabalho, como fizeram Itália e Espanha, respectivamente, com o parassubordinado e o autônomo economicamente dependente. No entanto, a intenção do estudo não é esgotar referidos institutos, mas somente trazer suas noções e breve histórico para propor reflexões sobre sua adoção pela legislação pátria.

O objetivo do estudo será também demonstrar que o bem-estar social somente pode ser alcançado com a união de todos que compõem a sociedade (Empresa, Trabalhador e Estado), uma vez que o Direito do Trabalho moderno constitui fator de integração social e solução de conflitos, não possuindo mais como única função proteger o trabalhador em face do poder econômico, mas também de coordenar interesses do capital e do trabalho, "o que exalta o seu importante papel de instrumento humanizador do direito econômico"2.

Assim, colocam-se as seguintes problemáticas: É possível a releitura extensiva do conceito clássico da subordinação jurídica? Existem formas para expandir o objeto do Direito do Trabalho sem alterar o conceito clássico de subordinação jurídica?

Para alcançar essa finalidade e responder a esses questionamentos, a dissertação foi estruturada em quatro capítulos. O primeiro analisa a evolução do trabalho humano, a origem e a redefinição do papel do Direito do Trabalho, uma vez que é

\footnotetext{
${ }^{2}$ NASCIMENTO, Amauri Mascaro, Perspectivas do Direito do Trabalho. In: FREDIANI, Yone; SILVA, Jane Granzoto Torres da (coords.). O direito do trabalho na sociedade contemporânea. São Paulo: Editora Jurídica Brasileira, 2001. p. 20.
} 
fundamental compreender as nuances que envolvem o assunto antes de adentrarmos no tema principal.

O segundo capítulo dedica-se aos elementos que constituem a relação empregatícia, dando especial atenção à subordinação, que, com o passar do tempo, de uma conotação técnica passou a econômica, social e moral até se consolidar como jurídica. Em seguida, destacar-se-á os fundamentos da subordinação, sua origem, natureza jurídica, influência que sofre das modernas tecnologias e o tratamento que recebe da Organização Internacional do Trabalho e dos ordenamentos jurídicos de outros países, como Portugal, Espanha, Itália e França.

O capítulo terceiro aborda as alterações no mundo do trabalho e seus reflexos na legislação, doutrina e jurisprudência, e os dois caminhos possíveis para enfrentálos: ampliar o objeto do Direito do Trabalho ou reformular o conceito de subordinação. Serão ainda expostas críticas em relação às teorias expansionistas do conceito de subordinação, destacando seus aspectos sociológicos, legais e os impactos que produzirão na cadeia produtiva. Por fim, destaca-se a importância do combate às fraudes, que prejudicam a sadia concorrência, os trabalhadores e o próprio Estado, que deixa de arrecadar impostos e se sobrecarrega suprindo e corrigindo os problemas causados pelos sonegadores trabalhistas.

O último capítulo explora a crise da divisão binária subordinação versus autonomia e as experiências italiana e espanhola que regulamentaram a modalidade intermediária. Também será mencionada a experiência brasileira que estendeu ao autônomo cooperado parte dos direitos exclusivos dos empregados, aumentando, assim, a tutela social aos hipossuficientes.

Desse modo, o estudo desenvolver-se-á por meio da análise dos dispositivos legais e constitucionais relacionados a cada uma das questões levantadas, além da análise da legislação e das doutrinas nacionais e estrangeiras. A brasileira para auxiliarnos na interpretação e entendimento do modelo nacional, bem como dar suporte para seu aprimoramento, e a estrangeira para termos conhecimento das soluções adotadas por outros sistemas jurídicos e, no que for proveitoso, sugerir a aplicação ao modelo brasileiro. 
Quanto à metodologia, optou-se pelos seguintes métodos: dialético, que se pauta em discussões doutrinárias divergentes; indutivo, que parte da análise da jurisprudência e de novas ideias para buscar visão mais ampla sobre os temas abordados e também suporte para as conclusões que se pretende propor; comparativo, para verificar a possível aplicação das experiências estrangeiras ao direito brasileiro e histórico, utilizado para análise da evolução da subordinação e do autônomo coordenado. No tocante ao método bibliográfico, foi empregado o regulamentado pelas normas da ABNT (Associação Brasileira de Normas Técnicas) e da Faculdade de Direito da Universidade de São Paulo. 


\section{CONCLUSÃO}

A partir da pesquisa realizada, evidencia-se que as mudanças na sociedade pós-industrial, advindas de Revoluções Industriais e Tecnológicas, de internacionalização dos mercados e extinção e surgimento de profissões levaram à crise do Direito do Trabalho. Assim, para que esse ramo da ciência jurídica continue acompanhando as transformações da sociedade, é necessário que se atualize.

Entretanto, qualificar como empregado quando ausentes os requisitos cumulativos da relação empregatícia, como propõem os defensores dos conceitos ampliativos de subordinação, é inadequado, uma vez que não aceitar as formas de trabalho autônomo e o fenômeno da terceirização é o mesmo que ignorar a legislação vigente e os princípios constitucionais como o da livre iniciativa, que também é um dos fundamentos da Constituição Federal juntamente com o da dignidade da pessoa humana e dos valores sociais do trabalho.

Conforme detalhado no presente estudo, as teorias expansionistas do conceito de subordinação tentam impor critérios imprecisos à condição de empregado e às formas de organização da produção, o que não atendem aos anseios do trabalhador contemporâneo e nem das empresas. A interpretação elástica da subordinação tende a alcançar o legítimo trabalhador autônomo, que prescinde da tutela do Direito do Trabalho.

É preciso não perder de vista que as leis que tratam da terceirização e do trabalho autônomo, validamente discutidas e promulgadas pelos representantes do povo e que observaram o processo legislativo que compõe o Estado Democrático de Direito, não podem ser simplesmente acoimadas de fraudulentas. A fraude será daquele que dela se serve para impedir a aplicação de direitos de outrem para aumentar seu lucro, desconfigurando ferramentas jurídicas válidas.

A partir de análise histórica e social, constatou-se que nem todos almejam a rigidez do contrato de emprego, que traz restrições à autonomia da vontade quando determina que o trabalhador deve se colocar à disposição para obedecer às ordens do 
empregador em troca de remuneração. Muitos profissionais buscam maior liberdade no trabalho e se dedicam a projetos pessoais, o que é incompatível com o poder diretivo inerente ao contrato de trabalho.

Ademais, a utilização combinada de empregados, autônomos e terceirizados, de acordo com as necessidades da atividade produtiva, além de beneficiar a sociedade em geral, que tem acesso a bens e serviços de melhor qualidade a menor preço, garante a sobrevivência das empresas, que não podem ser obrigadas a adotar modelos ultrapassados de produção e gestão, do contrário estará caracterizada indevida ingerência estatal na administração e nos rumos das sociedades empresárias.

Portanto, no contexto atual, são inaplicáveis as teorias expansionistas do conceito de subordinação, que poderão ser utilizadas como elementos auxiliares à subordinação jurídica clássica.

Para enfrentar a crise que vive o Direito do Trabalho, em vez de se alterar o conceito de subordinação, há a necessidade de redimensionar o Direito do Trabalho, com a incorporação ao ordenamento jurídico vigente do conceito intermediário entre autônomo e subordinado que permita fixar patamar mínimo de proteção aos trabalhadores que não se enquadram nas duas modalidades clássicas, ou seja, aos que se encontram nas chamadas zonas grises ou fronteiriças.

Para tratar desses trabalhadores, alguns países criaram novas categorias, como o parassubordinado, na Itália, e o autônomo economicamente dependente, na Espanha, com tutela adequada, sem a intensidade prevista para o subordinado e sem a ausência de direitos que caracteriza o autônomo, o que poderia ser adotado pela legislação brasileira, com a devida adequação do instituto à nossa realidade e às nossas necessidades, que são diferentes das dos países europeus.

Desta forma, se preencheria lacuna existente entre o trabalho subordinado e autônomo e, ao mesmo tempo, se ampliaria o campo de atuação do Direito do Trabalho, que tutela a parcela cada vez menor de trabalhadores subordinados.

Portanto, ao reconhecer a existência de outras modalidades de trabalho, o 
Direito do Trabalho não está negando sua identidade e suas tradicionais atribuições de proteção e redistribuição de riquezas, mas tão somente adaptando-se à realidade, tendo em vista que não é o Direito que molda o comportamento da sociedade, mas o contrário, pois apenas reflete determinado momento histórico.

A finalidade do presente estudo não é esgotar o tema, tendo em vista a amplitude do assunto, mas apresentar subsídios na busca de soluções para o aperfeiçoamento do Direito do Trabalho.

O grande desafio do Direito do Trabalho está em oferecer regulamentação adequada às novas modalidades de trabalho e às necessidades da sociedade contemporânea, conferindo proteção jurídica trabalhista e previdenciária aos que dela necessitam. 


\section{BIBLIOGRAFIA}

ALEMAN PAEZ, Francisco; CASTAN PEREZ-GOMEZ, Santiago. Del trabajo como hecho social al contrato de trabajo como realidad normativa: um apunte históricoromanístico. Madri: Dykison, 1997.

ALLEVA, Piergiovanni. Proposte di riforma della legislazione del lavoro (in risosta a Pietro Ichino). Rivista Giuridica del Lavoro e della Previdenza Social, Roma, EDIESSE, ano LVI, n. 1, jan./mar. 2005.

ALONSO OLEA, Manuel. Introdução ao direito do trabalho. Tradução de C. A. Barata Silva, em colaboração com Darci Rodrigues de Oliveira Santana. $4^{\mathrm{a}}$ ed. São Paulo: LTr, 1984.

ARAÚJO, Luiz Alberto David; e NUNES JÚNIOR, Vidal Serrano. Curso de direito constitucional. São Paulo: Verbatim, 2012.

AZEVEDO, André Jobim de. Relações contemporâneas de trabalho: observações. In: FREDIANI, Yone (coord.). A valorização do trabalho autônomo e a livre-iniciativa. Porte Alegre: Magister, 2015

BARASSI, Ludovico. Il contrato di lavoro nel diritto positivo italiano. Milano: Libraria, 1901, p. 29.

BARROS, Alice Monteiro de. Considerações gerais sobre o trabalho do vendedor-viajante e pracista. Revista do Tribunal Superior do Trabalho, Porto Alegre, ano 67, n. 3, p. 15, jul./set. 2001.

. Curso de direito do trabalho, $6^{\mathrm{a}}$ ed., São Paulo: LTr, 2010.

. Trabalhadores intelectuais: subordinação jurídica. Redimensionamento. Revista de Direito do Trabalho, vol. 115/2004. 
BARROS JÚNIOR, Cássio de Mesquita. Sujeitos do Contrato de Trabalho. In: MAGANO, Octavio Bueno (coord.). Curso de direito do trabalho: em homenagem a Mozart Victor Russomano. São Paulo: Saraiva, 1985.

BASTOS, Celso. Direito econômico brasileiro. São Paulo: IBDC, 2000.

BOISSONNAT, Jean. 2015 - Horizontes do Trabalho e do Emprego / relatório da comissão presidida por Jean Boissonnat; Tradução: Edilson Alkmim Cunha. São Paulo: LTr, 1998.

BORBA, Joselita Nepomuceno. Configuração jurídica da subordinação e sua importância na requalificação do contrato. Trabalho subordinado e trabalho autônomo. In: FREDIANI, Yone (coord.). A valorização do trabalho autônomo e a livre-iniciativa. Porte Alegre: Magister, 2015.

CATHARINO, José Martins. Compêndio de direito do trabalho, $2^{\mathrm{a}}$ ed. São Paulo: Saraiva, 1981.p. 181.

CAVALCANTE, Jouberto de Quadros Pessoa, Sociedade, tecnologia e a luta pelo emprego, 1. ed., São Paulo: LTr, 2018. p. 231.

CESARINO JR., A. F., Direito social brasileiro. $2^{\circ}$ vol. $6^{\text {a }}$ ed. Saraiva: São Paulo, 1970.

CHACON, G. Bayon e BOTIJA, E. Perez, Manual de Derecho Del Trabajo, vol. I, 9a ed. Madrid: D. Marcial Pons, 1974.

CHAVES JÚNIOR, José Eduardo de Resende; MENDEZ, Marcus Menezes Barberino. Subordinação estrutural-reticular: uma perspectiva sobre a segurança jurídica. Revista do Tribunal Regional do Trabalho da $3^{a}$ Região, Belo Horizonte, vol. 46, n. 76, p. 197-218, jul./dez. 2007

CNI. Sondagem Especial Indústria Total. Ano 4, n. 2, jul. 2014. 
COELHO, Fábio Ulhoa. Subordinação empresarial e subordinação estrutural. In: FREDIANI, Yone (coord.). A valorização do trabalho autônomo e a livre-iniciativa. Porte Alegre: Magister, 2015.

CRETELLA JÚNIOR, José. Enciclopédia Saraiva do Direito, v. 50, São Paulo: Saraiva, 1977.

D’ANTONA, Massino. Diritto del Lavoro di Fine Secolo: una crisi d'identità. in Rivista Giuridica Del Lavoro, ano 49, n. 1, Roma: Edisse, 1998.

DE BELLIS, Marco et al. L'ABC del lavoro parasubordinato. Milano: II Sole 24 Ore, 1998.

DEAKIN, Simon. Lavoro standard e lavori atipici nell'esperienza inglese: il ruolo del giudice, dela contrattazione e dela legge. In: PEDRAZZOLI, Marcelo (coord.). Lavoro subordinto e dintorni. Bologna: Il Mulino, 1989.

DELGADO, Maurício Godinho. Capitalismo, trabalho e emprego: entre o paradigma da destruição e os caminhos da reconstrução. São Paulo: LTr, 2006.

. Curso de Direito do Trabalho. 16 a ed. São Paulo: LTr, 2017.

. Direitos fundamentais na relação de trabalho. Revista LTr, São Paulo, LTr, ano 70 , n. 6 , p. 667 , jun. 2006.

. O Poder Empregatício. São Paulo: LTr, 1996.

DINIZ, Maria Helena. Compêndio de Introdução à Ciência do Direito. $23^{\mathrm{a}}$ edição, São Paulo: Editora Saraiva, 2011.

FELICIANO, Guilherme Guimarães. Dos Princípios do Trabalho no Mundo Contemporâneo. Revista LTr, São Paulo, LTR, ano 70, nº 4, p. 417-430, abril. 2006. 
FERNANDES, António de Lemos Monteiro. Direito do Trabalho. 13. Ed. Coimbra: Almedina. 2007.

FERRARI, Irany. Cooperativas de trabalho: existência legal. São Paulo: LTr, 1999. . História do trabalho, do direito do trabalho e da justiça do trabalho / FERRARI, Irany; NASCIMENTO, Amauri Mascaro; MARTINS FILHO, Ives Gandra da Silva. 2. ed., São Paulo: LTr, 2002.

FERRARO, Giuseppe. Dal lavoro subordinato al lavoro autonomo. Giornale di diritto del lavoro e di relazioni industriali, Milano, Franco Angeli, ano XX,nº 79, p. 429-507, 1998.

FERRAZ JÚNIOR, Tércio Sampaio. A Validade das Normas Jurídicas. $<$ http://www.egov.ufsc.br:8080/portal/sites/default/files/anexos/1064-1078-1-PB.pdf>. Acesso em 25/11/18. . Prefácio à obra Tópica e Jurisprudência, de Theodor Viehweg, Imprensa Nacional, Brasília, 1979.

FREDIANI, Yone, A quem o direito do trabalho deve proteger e o novo conceito de subordinação. Revista de Direito do Trabalho, vol. 160/2014. . Relações de trabalho no terceiro milênio e seus reflexos no mercado de trabalho. In: (coord.). A valorização do trabalho autônomo e a livre-iniciativa. Porte Alegre: Magister, 2015.

GALANTINO, Luisa. Diritto del lavoro. Torino: G. Giappichelli, 2006. . Intervento. Associazione Italiana di Diritto del lavoro e della Sicurezza Sociale (coord.). Impresa e nuovi modi di organizzazione del lavoro. Milano: Giuffrè, 1999.

GARCIA, Gustavo Filipe Barbosa. Curso de direito do trabalho. 5. ed. Rio de Janeiro: Forense, 2001. 
GARCÍA VIÑA, Jordi. O valor do trabalho autônomo e a livre-iniciativa. In: FREDIANI, Yone (coord.). A valorização do trabalho autônomo e a livre-iniciativa. Porte Alegre: Magister, 2015.

GASPAR, Danilo Gonçalves. Subordinação potencial: encontrando o verdadeiro sentido da subordinação jurídica. São Paulo: LTr, 2016. p. 200/201.

GILLESPIE, Tarleton. The Relevance of Algorithms. November 26, 2012, p. 1. Disponível em <http://culturedigitally.org/2012/11/the-relevance-of-algorithms/>. Acesso em: $13 \mathrm{dez}$. 2018.

GIGLIO, Wagner D.. Terceirização. LTr: Revista Legislação do Trabalho, São Paulo, v. 75, n. 4, abr. 2011.

GOMES, Orlando; GOTTSCHALK, Elson. Curso de Dreito do Trabalho. 16 ed. rev. e atual. por José Augusto Rodrigues Pinto. Rio de Janeiro: Forense, 2001.

HOUAISS, Antônio e VILLAR, Mauro de Salles. Dicionário Houaiss da Língua Portuguesa. Rio de Janeiro: Objetiva, 2001. p. 1277.

JORGE NETO, Francisco Ferreira e CAVALCANTE, Jouberto de Quadros Pessoa. Manual de Direito do Trabalho, Rio de Janeiro: Editora Lumen Juris, 2003.

KELSEN, Hans. Teoria geral do direito e do estado. Tradução: Luís Carlos Borges. São Paulo: Martins Fontes, 2000.

KELSEN, Hans. Teoria Pura do Direito. Tradução: João Baptista Machado. 6. ed. São Paulo: Martins Fontes, 1998.

KLEINBERG, Jon. The Mathematics of Algorithm Design. Princenton Companion to Mathematics, 2008, $\quad$ p. $1 . \quad$ Disponível em $<$ https:www.cs.cornell.edu/home/kleinber/pcm.pdf $>$. Acesso em: 12 dez. 2018. 
LISO, Francesco. Brevi note a proposito dell'iniziativa legislativa in materia di lavori atipici. Diritto del lavoro on line. Disponível em: $<$ http://www.unicz.it/lavoro/LISO.htm.>. Acesso em: 13 nov. 2018.

LOY, Gianni. El dominio ejercido sobre el trabajador. Relaciones Laborales: revista critica de teoria y practica, Madrid, La Ley, n. 2, p. 165-189, 2005.

MACHADO, Sidnei. A noção de subordinação jurídica: uma perspectiva reconstrutiva. São Paulo: LTr, 2009.

MAGANO, Octávio Bueno. ABC do direito do trabalho. $2^{\text {a }}$ ed. São Paulo: Editora Revista dos Tribunais, 2000.

. As novas tendências do Direito do Trabalho. São Paulo: LTr. 1974.

. Manual de Direito do Trablho. $3^{\circ}$ ed. São Paulo: LTr. 1993.

MANNRICH, Nelson, A modernização do contrato de trabalho. São Paulo: LTr, 1998.

. Direito do Trabalho em tempos de crise: qual a medida da reforma? Revista do Tribunal Regional do Trabalho da $1^{a}$ Região - jan/jun 2016. n 58.

. Legislação trabalhista: garantia de patamares mínimos, In: ROMAR, Carla Tereza Martins; SOUZA, Otávio Augusto Reis de (Coords.). Temas relevantes de direito material e processual do trabalho - estudos em homenagem ao Professor Pedro Paulo Teixeira Manus, p. 569/586, São Paulo, LTr, 2000.

. Prefácio, In: WINTER, Vera Regina Loureiro. Teletrabalho: uma forma alternativa de emprego. São Paulo: LTr, 2005.

Reinventando o Direito do Trabalho: novas dimensões do trabalho autônomo. In: FREDIANI, Yone (coord.). A valorização do trabalho autônomo e a livre-iniciativa. Porte Alegre: Magister, 2015. 
MANUS, Pedro Paulo Teixeira. A subordinação jurídica no contrato individual de trabalho. In: FREDIANI, Yone (coord.). A valorização do trabalho autônomo e a livre-iniciativa. Porte Alegre: Magister, 2015. . Direito do Trabalho. 9a ed. São Paulo: Atlas, 2005.

MARTINEZ, Luciano. Curso de direito do trabalho: relações individuais, sindicais e coletivas do trabalho. 6. ed. - São Paulo: Saravia, 2015.

MARTINEZ, Pedro Romano. Código do trabalho: anotado / coord. Pedro Romano Martinez ... [et al.]. 10 ed. Coimbra: Almedina.

MARTINS, Sérgio Pinto. Cooperativas de trabalho, 5. ed., São Paulo: Atlas, 2014. . Direito do trabalho, 29a ed., São Paulo: Atlas, 2013.

MAZEUD, Antoine. Droit du travail. 7. ed. Paris: Éditions Montcrestien, 2010.

MAZZONI, Giuliano. Manuale di diritto del lavaro. Milano: Giuffrè, 1977. v. 1.

MELGAR, Alfredo Montoya. Derecho del Trabajo, 19ª ed. 1998. Madrid: Editorial Tecnos.

MENDONÇA, José Xavier Carvalho de. Tratado de direito comercial brasileiro. Rio de Janeiro: Freitas Bastos, 1954.

MORA, Fréderic López I. Trabajo autônomo, Estado Social y la expansión de su Estatuto. In: PANEDERO, Purificación Morgado (Coord.). Trabajo Autónomo e Igualdad: Reflexiones desde el Derecho del Trabajo. Aranzadi: Cizur Menor, 2010.

MORAES, Evaristo de. Apontamentos de direito operário. $4^{\mathrm{a}}$ ed. São Paulo: LTr, 1998.

MORAES FILHO, Evaristo de. Introdução ao direito do trabalho. 4. ed. São Paulo: LTr, 1986. 
. Tratado Elementar de Direito do Trabalho, v. 1, Rio de Janeiro: Freitas Bastos, 1960.

MÜCKENBERGER, Ulrich; WALK, Rolf; BUCHNER, Herbert. Ridefinire la nozione di subordinazione? Il dibattio in Germania. Giornale di diritto del lavoro e di relazioni industriali, Milano, Franco Angeli, ano XXII, n. 86, 2000.

NAPOLI, Mario. I rapporti di collaborazione coordinata e continuativa. Associazione Lavoro e Ricerche (coord.). Autonomia negoziale e prestazioni di lavoro. Milano: Giuffrè, 1993.

NASCIMENTO. Amauri Mascaro. Direito contemporâneo do trabalho. São Paulo: Saraiva, 2011.

. Curso de direito do trabalho. $29^{\mathrm{a}}$ ed. São Paulo: Saraiva, 2014.

. Perspectivas do Direito do Trabalho. In: FREDIANI, Yone; SILVA, Jane

Granzoto Torres da (coords.). O direito do trabalho na sociedade contemporânea. São Paulo: Editora Jurídica Brasileira, 2001.

. Um terceiro caminho para o direito do trabalho. In: . A transição do direito do trabalho no Brasil: estudos em homenagem a Eduardo Gabriel Saad. São Paulo: LTr, 1999. P. 15-16.

OLIVEIRA, José César de. Formação Histórica do Direito do Trabalho. In: BARROS, Alice Monteiro de (coord.). Curso de direito do trabalho: estudos em memória de Célio Goyatá, São Paulo: LTr, 1993.

PINTO, Almir Pazzianotto. Cooperativas. Organização Internacional do Trabalho. Cooperativa: mudanças, oportunidades e desafios / editado Armand Pereira; em colaboração com Lucienne Freire e Lizzie Lagana. 1. Ed. Brasília: OIT, 2001. 
PINTO, Almir Pazzianoto. Subordinação estrutural e a legislação trabalhista. In: FREDIANI, Yone (coord.). A valorização do trabalho autônomo e a livre-iniciativa. Porte Alegre: Magister, 2015.

PEDREIRA, Luiz de Pinho, Principiologia do direito do trabalho. São Paulo: LTr, 1993. v. 1.

. Da velha parassubordinação ao novo contrato a projeto. In: Artigo da Escola da Magistratura do Trabalho da Paraíba. Disponível em: $<$ http://esmat13.com.br/art_normal.php?id.noticia=935>. Acesso em: 16 nov. 2018.

PÉLISSIER, Jean; AUZERO, Gilles; DOCKÈS, Emmanuel. Doroit du travail. 26. ed. Paris: Éditions Dalloz, 2011.

PERONE, Giancarlo. Lineamenti di diritto del lavoro. Torino: G. Giappichelli, 1999.

PINO, Giovanni. Il contesto di inizio secolo e la discussione sul contrato di lavoro. PEDRAZZOLI, Marcelo (coord.). Lavoro subordinato e dintorni. Bologna: Il Mulino, 1989.

PINTO, José Augusto Rodrigues. Curso de direito individual do trabalho. $4^{\circ}$ ed. São Paulo: LTr, 2000. . Por que ter medo da terceirização brasileira? LTr: Revista Legislativa do Trabalho. São Paulo, v. 75, n. 11, nov. 2011.

PORTO, Lorena Vasconcelos. A Subordinação No Contrato De Trabalho: Uma Releitura Necessária. São Paulo: LTR, 2009.

REIS, Daniela Muradas; CORASSA, Eugênio Delmaestro. Aplicativos de Transporte e Plataforma de Controle: o mito da tecnologia disruptiva do emprego e a subordinação por algoritmos. In: LEME, Ana Carolina Reis Paes; RODRIGUES, Bruno Alves; CHAVES JÚNIOR, José Eduardo de Resende (coords.). Tecnologias disruptivas e a exploração do trabalho humano. São Paulo: LTr, 2017. 
RENAULT, Luiz Otávio Linhares; MEDEIROS, Dárlen Prietsch. A Subordinação Sem Derivações Semânticas. In: ; CANTELLI, Paula Oliveira; PORTO, Lorena Vasconcelos; NIGRI, Fernanda (coords.). Parassubordinação: Homenagem ao Professor Márcio Túlio Viana. São Paulo: LTR, 2011.

. Parassubordinação: Para quê? In: ; CANTELLI, Paula Oliveira;

PORTO, Lorena Vasconcelos; NIGRI, Fernanda (coords.). Parassubordinação: Homenagem ao Professor Márcio Túlio Viana. São Paulo: LTR.

Repertorio de foro italiano, ano de 1913, Roma: Il Foro Italiano, 1914.

Repertorio de foro italiano, ano de 1916, Roma: Il Foro Italiano, 1917.

Repertorio de foro italiano, ano de 1938, Roma: Il Foro Italiano, 1939.

ROBORTELLA, Luiz Carlos Amorim; PERES, Antônio Galvão. Subordinação estrutural na terceirização de serviços. Subversão dogmática. In: FREDIANI, Yone (coord.). $A$ valorização do trabalho autônomo e a livre-iniciativa. Porte Alegre: Magister, 2015. O moderno direito do trabalho. São Paulo: LTr, 1994.

ROCHA, Osiris. A subordinação e sua insuficiência para integral visualização do contrato individual de trabalho. Revista do Tribunal Superior do Trabalho, São Paulo: LTr, ano 1977.

RODRIGUES, Bruno Alves. Novo paradigma de subordinação na relação de emprego. TRT $3^{\text {a }}$ Reg. Belo Horizonte, v.39, n.69, jan./jun.2004.

RODRIGUEZ, Américo Plá. Curso de Direito do Trabalho. Tradução: João da Silva Passos. São Paulo: LTr, 1982. . Princípios de Direito do Trabalho. Tradução: Wagner D. Giglio. São Paulo: LTr, 1982. 
Organização Internacional do Trabalho. Cooperativa: mudanças, oportunidades e desafios / editado Armand Pereira; em colaboração com Lucienne Freire e Lizzie Lagana. 1. Ed. Brasília: OIT, 2001.

ROMITA, Arion Sayão. A Crise do Critério da Subordinação Jurídica. Revista de Direito do Trabalho, São Paulo: Revista dos Tribunais, n. 117, 2005.

. A Subordinação no contrato de trabalho. Rio de Janeiro: Forense, 1979.

. Direito do Trabalho: temas em aberto. São Paulo: LTr, 1998.

RUPRECHT, Alfredo J. Os princípios do direito do trabalho. Tradução: Edilson Alkmin Cunha. São Paulo: LTr, 1995.

. Relações coletivas de trabalho. Tradução: Edilson Alkimin Cunha. São Paulo: LTr, 1995.

RUSSOMANO, Mozart Victor. Curso de Direito do Trabalho. $5^{\text {a }}$ edição. Curitiba: Juruá, 1995.

. O Empregado e o Empregador no Direito Brasileiro, 6 a ed., São Paulo: LTr,

1978.

SAGARDOY BENGOECHEA, Juan Antonio; GIL Y GIL, José Luis. Supuestos Incluidos. In: BAUDOR, Guilhermo L. Barrios (Coord.). Comentarios al Estatuto del Trabajo Autónomo. Aranzadi: Cizur Menor, 2010.

SANSEVERINO, Luisa Riva. Curso de direito do trabalho. Trad. Elson Gottschalk. São Paulo: LTr, 1976.

SANTORO-PASSARELLI, Francesco. Noções de direito do trabalho. Tradução: Mozart Victor Russomano e Carlos Alberto G. Chiarelli. São Paulo: Revista dos Tribunais, 1973. 
SARLET, Ingo Wolfgang. Curso de direito constitucional. 2 ed. São Paulo: RT, 2013.

SCHWAB, Klaus. A quarta revolução industrial; Tradução: Daniel Moreira Miranda. São Paulo: Edipro, 2016.

SILVA, Antônio Álvares da. Flexibilização nas relações de trabalho. São Paulo: LTr, 2002.

SILVA, José Afonso da. Curso de direito constitucional positivo. 26. ed. São Paulo: Malheiros, 2006.

SILVA, Otávio Pinto e. Subordinação, autonomia e parassubordinação nas relações de trabalho. São Paulo: LTr, 2004.

SIQUEIRA NETO, José Francisco, Princípios de direito do trabalho e economia de mercado. In: FREDIANI, Yone; SILVA, Jane Granzoto Torres da (coords.). O direito do trabalho na sociedade contemporânea. São Paulo: Editora Jurídica Brasileira, 2001.

SOUTO MAIOR, Jorge Luiz. A Supersubordinação. In: RENAULT, Luiz Otávio Linhares; CANTELLI, Paula Oliveira; PORTO, Lorena Vasconcelos; NIGRI, Fernanda (coords.). Parassubordinação: Homenagem ao Professor Márcio Túlio Viana. São Paulo: LTR, 2011.

STÜRMER, Gilberto. A Terceirização de mão de obra frente à proibição do retrocesso dos direitos sociais do trabalhador. In: SARLET, Ingo Wolfgang; STRAPAZZON, Carlos Luiz; GOMES, Eduardo Biacchi (Org.). I Jornada sul-americana de direitos fundamentais: Brasil, Argentina, Chile e Peru. 1ed. Joaçaca/SC: Editora Unoesc, 2015, p. 357-362.

SUPIOT, Alan. Au-delà de l'emploi: Trasformations du travail ET devenir du droit du travail en Europe. Paris: Falmmarion, 1999. . Les nouveaux visages de la subordination. Droit Social, Paris, Techniques et Économiques, n. 2, p. 131-145, fev. 2000.

TESAURO, Paula et al. II raporto di lavoro: subordinazione e costituzione. Milano: UTET, 1993. v. 1. 
THIBAULT ARANDA, Javier. El teletrabajo: analisis jurídico-laboral. $2^{\circ}$ ed. Madrir: Consejo Economio y Social, 2001.

VALLEBONA, Antonio. Istituzioni di diritto del lavoro. 2. ed. Torino: G. Giappichelli, 2000.

VIANNA, Segadas. Duas Revoluções: A Jurídica e a Econômica. In: Arnaldo Süssekind et al. Instituições de Direito do Trabalho, v. I, $18^{\mathrm{a}}$ ed., São Paulo: LTr, 1999.

VILHENA, Paulo Emílio Ribeiro de. Relação de emprego. Estrutura legal e supostos. 3. ed. São Paulo: LTr, 2005.

WANK, Rolf. Diversifying employment patterns - the scope of labour law and the notion of employees. Disponível em

$<$ http://www.jil.go.jp/english/events_and_information/documents/clls04_wank2.pdf.> Acesso em: 10 set. 2018.

WANK, Rolf. Worker's protection national study for Germany for the ILO. Disponível em: $<$ http://www.ilo.org/public/english/dialogue/ifpdial/downloads/wpnr/germany.pdf $>$. Acesso em: 10 set. 2018. 